\title{
Dilemas do feminismo e a possibilidade de radicalização da democracia em meio às diferenças

\author{
O caso da Marcha das Vadias do Rio de Janeiro
}

\author{
Feminists dilemmas and the possibility of radicalizing \\ democracy in the midst of differences \\ The Slut Walk of Rio de Janeiro
}

\author{
Letícia Ribeiro \\ Brena O'Dwyer \\ Maria Luiza Heilborn
}

\begin{abstract}
Resumo: O objetivo do artigo é analisar maneiras pelas quais a tensão entre igualdade e diferença é debatida no feminismo contemporâneo, bem como as implicações em termos de possibilidades e desafios para a efetivação da democracia. A metodologia consistiu em observação participante realizada em eventos e reuniões organizados por ativistas da Marcha das Vadias do Rio de Janeiro, entre maio e agosto de 2014. Nos anos seguintes, acompanhamos essa e outras iniciativas feministas do Rio de Janeiro, bem como os debates online entre diversas correntes ideológicas atuais, particularmente transfeministas, "feministas radicais" e feministas negras. As conclusões apontam para o uso do conceito de interseccionalidade como possibilidade de resolução das diferenças em uma perspectiva de combate às opressões. Uma tensão ainda não resolvida é a possibilidade de radicalização da democracia, expressa no ideal de "horizontalidade", visto pelas militantes como não efetivado nas interações.
\end{abstract}

Palavras-chave: Igualdade e diferença. Marcha das Vadias. Transfeminismo. Feminismo negro. Interseccionalidade.

\footnotetext{
* Mestra em Saúde Coletiva pelo Instituto de Medicina Social da Universidade do Estado do Rio de Janeiro (IMS/Uerj) e doutoranda em Sociologia e Antropologia pelo Programa de Pós-Graduação em Sociologia e Antropologia da Universidade Federal do Rio de Janeiro (PPGSA/UFRJ) no Rio de Janeiro, RJ, Brasil<lettribeiro@gmail.com>.

** Mestra em Saúde Coletiva pelo Instituto de Medicina Social da Universidade Estadual do Rio de Janeiro (IMS/Uerj) e doutoranda em Antropologia Social pelo Programa de PósGraduação em Antropologia Social do Museu Nacional, da Universidade Federal do Rio de Janeiro (PPGAS/MN/UFRJ) no Rio de Janeiro, RJ, Brasil<brenaspina@gmail.com>.

***Doutora em Antropologia Social pelo Programa de Pós-Graduação em Antropologia Social do Museu Nacional, da Universidade Federal do Rio de Janeiro, (PPGAS/MN/UFRJ) e Professora no Instituto de Medicina Social da Universidade Estadual do Rio de Janeiro (IMS/ Uerj) no Rio de Janeiro, RJ, Brasil <marialuiza.heilborn@gmail.com>.
} 
Abstract: This article analyzes the tension between equality and difference in
contemporary Brazilian feminism and the implications of this discussion to the
challenges of implementing and expanding democracy. The main methodological
resource was participant observation of the events and reunions of the Rio de Janeiro
Slutwalk activists between may and august 2014. In the years following, other
feminists initiatives at Rio de Janeiro were monitored as well as intense online debate
between different feminists contemporary ideologies, especially transfeminism, radical
feminism and black feminism. The conclusions point to the use of the concept of
"interseccionality" as a way of dealing with differences and combating oppression.
Even so, the tension expressed by the militants in the ideal of "horizontality" remains
and indicates the challenges of radicalization of democracy.

Keywords: Equality and difference. Slutwalk. Transfeminism. Black feminism. Interseccionality.

\section{Introdução}

Nos últimos anos, no Brasil, o feminismo vem tomando as ruas e redes sociais virtuais, em movimento que começou a ser chamado na mídia de "primavera das mulheres". Em outubro de 2015, mensagens de teor sexual sobre Valentina, participante de doze anos de um programa de TV, resultaram na campanha "Primeiro Assédio", em que mulheres relataram nas redes sociais as primeiras vezes em que foram assediadas, em grande parte, ainda crianças. No Exame Nacional do Ensino Médio (Enem), no mesmo ano, a escolha do tema da redação "violência de gênero", bem como a inclusão de um trecho da filósofa feminista Simone de Beauvoir em uma das questões, expôs novamente o tema. O projeto de lei de autoria do então presidente da câmara Eduardo Cunha (PMDB-RJ), que pretendia dificultar o acesso de vítimas de violência sexual ao aborto $\mathrm{e}$ a contraceptivos de emergência, levou milhares às ruas.

Nota-se, na atualidade, um cenário de embates entre setores conservadores e grupos pró-igualdade de gênero e diversidade sexual. Nesse contexto, o ideário feminista propaga-se e ganha a adesão de uma geração de mulheres cada vez mais jovens, com a multiplicação de coletivos universitários e secundaristas. Identifica-se uma pluralidade de tendências ideológicas, dentre as quais se destaca o feminismo interseccional.

O conceito de interseccionalidade foi primeiramente cunhado por Kimberlé Crenshaw (1989), e refere-se à noção de que "gênero" e "raça" atuam de forma articulada na produção de desigualdades e hierarquias. A autora critica tanto o feminismo quanto o movimento negro, que, ao acionarem categorias gerais de "mulheres" e de "comunidade negra", respectivamente, estão centrados nos grupos mais privilegiados, seja em termos de classe e raça, seja em termos de classe e gênero. Desse modo, em nenhum desses 
movimentos políticos é feita, segundo a autora, uma reflexão sobre o modo particular pelo qual as mulheres negras são subordinadas.

A diversidade é central para o debate proposto pelo feminismo interseccional, que busca articular a luta feminista ao combate a outras formas de opressão, sendo enfatizadas as diferenças entre as mulheres. $\mathrm{Na}$ contemporaneidade, um dos desdobramentos dessa perspectiva é o chamado transfeminismo, pautado por demandas de mulheres transexuais - aquelas que não se identificam com o gênero atribuído no nascimento a partir da genitália.

As transfeministas argumentam que, para além de reivindicações específicas, as mulheres trans também sofrem com o machismo e a misoginia, o que justificaria sua inclusão nos movimentos feministas. Contudo, a participação de mulheres trans no feminismo contemporâneo não é consensual. Karla Galvão Adrião et al. (2011) descrevem os debates ocorridos no $10^{\circ}$ Encontro Feminista Latino-Americano e do Caribe (2005) em torno da possibilidade de participação de transgêneros no Encontro seguinte. Os argumentos favoráveis à participação de mulheres trans afirmavam que é possível definir-se como mulher sem ter nascido com o corpo biológico feminino, enquanto as ativistas contrárias acreditavam que isso significaria a entrega dos espaços de poder aos homens. Ao final foi acatada a decisão da maioria, que votara a favor da participação.

Corrente ideológica contrária à inclusão de mulheres trans é aquela que congrega as Terfs, isto é, trans exclusionary radical feminists, ${ }^{1}$ que se caracteriza pelo entendimento de que as demandas de mulheres transexuais não seriam propriamente feministas. Ativistas dessa vertente rechaçam mulheres trans, enfatizando a socialização masculina que receberam e a falta de experiências femininas, tais como a menstruação. Nesse caso, as mulheres trans são negadas em sua identidade e tratadas como homens. Em outro tipo

\footnotetext{
${ }^{1}$ O termo "Terf" surge como categoria de acusação a essas ativistas, caracterizadas como transfóbicas por aquelas favoráveis a inclusão de mulheres trans no feminismo. Posteriormente, o termo é incorporado pelas próprias ativistas defensoras da não participação de trans, que, nesse caso, não atribuem à nomeação um caráter negativo. A expressão geralmente é traduzida como "feministas radicais trans-exclusionárias", sendo comum o uso mais simplificado de "feministas radicais". Importante atentar para o fato de que nem todas as feministas radicais são trans-exclusionárias. Além disso, importante não confundir o feminismo radical contemporâneo no Brasil com o feminismo radical, especialmente americano, dos anos 1970 e 1980. Este surgiu na segunda onda do feminismo e tinha como principal conceito o de patriarcado, que seria um sistema de opressão das mulheres trans-histórico. Assim, as feministas radicais dos anos 1970 pretendiam eliminar a supremacia masculina em todos os âmbitos. Entretanto, como discutimos no artigo, essas distinções são nuançadas e muitas feministas Terfs contemporâneas têm ideias similares às de feministas radicais da década de 1970. Pretendemos neste artigo justamente apresentar a polifonia do movimento e não resolver qualquer uma destas questões ou apresentar categorias congeladas.
} 
de argumentação, aceita-se a identidade de gênero das mulheres trans, mas entende-se que elas teriam demandas diferentes das do feminismo, e por isso deveriam articular-se em movimento político distinto.

Neste artigo, partimos da Marcha das Vadias do Rio de Janeiro, localizando-a em meio a diversas correntes do feminismo contemporâneo, especificamente o transfeminismo e o feminismo negro. A metodologia consistiu em observação participante realizada entre maio e agosto de 2014. Participamos, ao longo daquele ano, de reuniões, debates e rodas de conversa promovidas por ativistas envolvidas na organização desta Marcha. Ao longo do trabalho de campo, verificou-se que os debates pautavam questões relativas à identidade e diferença no feminismo, bem como à possibilidade de um tipo de atuação política que suavizasse hierarquias entre mulheres (Ribeiro, 2016). Nos anos seguintes, acompanhamos essa e outras iniciativas feministas do Rio de Janeiro, bem como os debates online entre diversas correntes ideológicas atuais.

Nosso objetivo é analisar maneiras pelas quais a tensão entre igualdade e diferença, debate clássico na história dos movimentos feministas e dos estudos de gênero, é reatualizado nos feminismos contemporâneos. De modo mais amplo, estamos interessadas nas possibilidades e desafios para a ampliação da democracia.

\section{Potencialidades e limites da categoria política "vadia": o sujeito político do feminismo}

A Marcha das Vadias inspira-se em movimento iniciado em fevereiro de 2011 na cidade de Toronto, Canadá, com o nome de Slutwalk. De acordo com o site oficial dessa Marcha, o movimento se originou como resposta à fala, de um representante da polícia, em uma palestra sobre segurança no campus na Universidade de Toronto: "As mulheres deveriam evitar se vestir como vadias a fim de não serem vitimadas". A partir da concepção de que tal fala demonstra que as instituições policiais reforçam mitos sobre a violência sexual que auxiliam na culpabilização das vítimas, feministas saíram às ruas de Toronto seminuas ou com roupas consideradas provocantes. Com cartazes e frases desenhadas em seus corpos, reivindicavam que as vítimas não sejam culpabilizadas pelas agressões que sofreram. Difundindo-se por meio de redes sociais e blogs na internet, o movimento rapidamente globalizou-se, já tendo ocorrido em diversos países.

As organizadoras da primeira slutwalk argumentam que a unidade do movimento não se deve a um sujeito político unívoco, enfatizando a heterogeneidade de mulheres que pretendem incluir na luta. Na realidade, o sujeito político sequer se restringe às mulheres, como demonstrado pela 
seguinte passagem: “We Are Coming Together. Not only as women, but as people from all gender expressions and orientations [...]" [grifo no original]. ${ }^{2}$ Em consonância com essa perspectiva, no Rio de Janeiro constata-se a presença de travestis e transexuais envolvidas na organização da Marcha das Vadias.

A frase "Se ser livre é ser vadia, então somos todas vadias!", presente em cartazes em grande parte das Marchas, expressa a possibilidade de alianças entre pessoas diferentes a partir da defesa da liberdade. Algumas feministas, no entanto, criticam o uso do termo "slut", argumentando que tal categoria exclui determinados grupos sociais. Nesse sentido, a dimensão racial é especialmente delicada, devido a estereótipos relativos à suposta sexualidade exacerbada das mulheres negras (Heilborn e Cabral, 2008). No blog intitulado Feminista Cansada, postou-se a tradução de "uma carta aberta de mulheres negras à Marcha das Vadias", publicada originalmente no site Black Women's Blueprint. Nela, ativistas de movimentos de mulheres negras argumentam que a Marcha não consegue representar experiências particulares de mulheres de diferentes raças e etnias. Para elas, normalizar o termo "vadia" significaria reafirmar representações machistas sobre a mulher negra, pois esse termo e outros correlatos sempre foram utilizados para "desumanizá-la". ${ }^{3}$

Assim, as slutwalks valorizam a diversidade, mas são confrontadas por críticas que denunciam que o termo "slut" é excludente. Tais críticas estão fundadas na reivindicação de identidades específicas, baseadas em diferenças, e expressam antigo dilema do feminismo: o debate sobre igualdade/ diferença, delineado a partir de pensadoras pós-coloniais, mulheres negras e feministas lésbicas, que denunciam que o feminismo se fortaleceu a partir da universalização de leituras de mulheres brancas, europeias, heterossexuais e de classe média (Mayorga et al., 2013).

\section{Os dilemas da identidade}

O feminismo sempre foi polifônico e precisou lidar ao longo de sua história com a crise da ideia de essência e ontologia feminina. Os feminismos contemporâneos, especialmente por razão dos questionamentos das feministas negras e trans, revivem esse debate. Butler (2003) descreve como o gênero se torna inteligível a partir de uma matriz heterossexual que conforma uma coerência entre gênero, sexo e desejo, criticando a unicidade do sujeito político do feminismo, "mulher". A autora aponta para um paradoxo nas políticas

\footnotetext{
${ }^{2}$ Why. <slutwalktoronto.com/about/why/> (18 jul. 2014).

${ }^{3}$ Uma carta aberta de mulheres Negras para a Marcha das Vadias $<$ feministacansada.com/ post/44143444731> (25 fev. 2015).
} 
identitárias, que ao pretenderem libertar os sujeitos acabam prendendo-os em categorias, e argumenta que pode haver luta política para além das identidades fixas.

Tal debate remete a uma questão ontológica amplamente debatida no feminismo desde a seminal frase "não se nasce mulher, torna-se" de Beauvoir (1960). Nos anos 1960, o debate acerca do estatuto da diferença ocorria a partir da oposição entre "feminismo da igualdade" e "feminismo da diferença". A primeira posição entendia a tarefa política do feminismo como a distribuição igualitária de bens e direitos entre homens e mulheres, suprimindo as diferenças entre os dois. Já o "feminismo da diferença" argumentava que a supressão das diferenças ocorreria através de um assimilacionismo e de uma concepção de mundo androcêntrica e pretendia, em contraponto, valorizar a diferença de gênero, especialmente a feminilidade. Carla Rodrigues (2009) argumenta que a dicotomia igualdade e diferença seria falsa, sendo o segundo termo da oposição, a desigualdade. A autora descreve como desde a Revolução Francesa as mulheres tomaram dois caminhos nas lutas por direitos.

O primeiro exige que o ideal de cidadania alcançado pelos homens seja estendido às mulheres, de tal forma que a sociedade seja "neutra em termos de gênero". O segundo [...] defende que as mulheres têm capacidades, talentos, necessidades e preocupações específicas, que devem ser levados em conta na sua cidadania [...] a lógica da sociedade patriarcal sustentaria que os dois caminhos seriam incompatíveis porque o patriarcado permite apenas que se opte entre duas alternativas: tornar-se mulher "como homens", e assim, sujeito de direitos, ou valorizar a especificidade das mulheres, que não confere nenhum valor para torná-las cidadãs (Rodrigues, 2009, p. 122).

O caminho que afirma a especificidade da mulher pode ser criticado (Rodrigues, 2009) por trazer o "risco de retorno do essencialismo". Entretanto, Carla Rodrigues chama a atenção de que Joan Scott já argumentava que a oposição igualdade/diferença é análoga à natureza/cultura e a masculino/ feminino, e, portanto, reitera a hierarquia de gênero. A autora então recorre a Jacques Derrida para indicar que qualquer oposição implica uma hierarquia. Assim, "ao reforçar a defesa identitária a política feminista corre o risco de sustentar a mesma hierarquia que pretendia descontar" (Rodrigues, 2009, p. 121).

Heleieth Saffioti (2016) também aponta para as armadilhas de pensar a igualdade e a diferença como par dicotômico, permeando a noção de identidade de um essencialismo. A autora argumenta que pensar a ambiguidade do gênero é crucial como estratégia para um feminismo com sujeitos múltiplos. 
Preciado (2011) argumenta a favor de uma política de "multidão queer" indicando que não há qualquer base natural como "mulher" ou "gay" que possam legitimar a ação política. Portanto, defende uma "desontologização das políticas de identidades". Segundo a autora, nos anos 1980, o debate feminista entre "construtivistas" e "essencialistas" leva ao surgimento do conceito de gênero como a construção sócio-histórica da diferença sexual, de encontro com a ideia de "feminilidade" como "verdade ontológica" (Preciado, 2011, p. 13). Tal debate volta à tona de forma aguda com as demandas de mulheres trans por espaço no feminismo.

\section{O "novo feminismo" ou a "quarta onda do feminismo": rumo à desconstrução?}

Em um momento histórico em que diversas conquistas estão sob ameaça, e no qual o tema gênero e sexualidade parece ser um importante foco de ataque, a constatação de uma nova geração de feministas aponta para a possibilidade de resistência ao retrocesso conservador.

Entre acadêmicas, o momento atual por vezes é associado ao surgimento de uma "quarta onda do feminismo". Nos estudos feministas, a classificação em "ondas" faz referência a momentos de transformações em que despontam novas prioridades, métodos e protagonistas. ${ }^{4}$ Parte relevante do que vem sendo chamado de "novo feminismo" ou "quarta onda feminista" refere-se à atenção devotada às diferenças e desigualdades entre as mulheres. ${ }^{5}$ Nesse sentido, a categoria de "interseccionalidade" é central nos discursos de diversas militantes, de modo que a mulher não é entendida como uma categoria unitária ou um sujeito político unívoco. Seguindo a maneira como geralmente são caracterizadas as ondas do feminismo, o entendimento geral é o de que o momento atual radicaliza um processo de desconstrução que vem desde a terceira onda, quando as teorias pós-modernas questionaram a noção de identidade, afirmando a diversidade e configurando a possibilidade de outros sujeitos de direito, que não se conformam ao binarismo de gênero (Heilborn, 2016). Nessa narrativa, o "novo feminismo", além de "jovem", seria marcado pela desconstrução e pela recusa do essencialismo.

\footnotetext{
${ }^{4}$ A periodização por ondas divide a história do feminismo brasileiro em três fases. A chamada primeira onda refere-se às reivindicações pelo direito ao voto no século 19. A segunda onda do feminismo brasileiro esteve ligada à luta contra a ditadura nos anos 1970. A terceira onda, que teve início na década de 1990, é marcada pela desconstrução do conceito de gênero.

5 Significativamente, o dossiê da revista Cult intitulado "A quarta onda", publicado em dezembro de 2016, traz como chamada: "A revolução será feminista, negra, jovem, vadia, queer, ou não será".
} 
A leitura em termos de "ondas" tem sido, no entanto, objeto de debate. Clare Hemmings (2009) questiona as narrativas dominantes sobre o feminismo ocidental, demonstrando que elas tendem a fixar as perspectivas de modo a construir uma narrativa teleológica de progresso ou perda. O pressuposto da autora é o de que as estórias do passado são feitas e refeitas tendo em vista legitimar determinado presente. São, portanto, uma questão de poder e autoridade.

Assim, "proclamar um momento histórico como uma 'nova onda' confere poder aos seus enunciadores e valoriza a sua agenda política" (Gomes e Sorj, 2014, p. 436), não sendo, portanto, uma caracterização neutra. Ainda, caso empreendida de modo excessivamente linear, obscurece disputas internas ao feminismo (Gomes, 2016), tais como o clássico debate sobre igualdade/ diferença e a possibilidade de legitimação de sujeitos feministas plurais, reatualizado nas manifestações contemporâneas. Conforme procuraremos demonstrar, em que pese a importância geral atribuída à interseccionalidade - expressão e efeito da legitimidade conquistada pelos movimentos de mulheres negras -, as possibilidades e limites da desconstrução do conceito de gênero são objeto de intensas disputas, o que se evidencia na tensão entre "transfeministas" e algumas "feministas radicais".

\section{Qual o lugar do transfeminismo?}

As ativistas da Marcha das Vadias do Rio de Janeiro eram majoritariamente brancas, jovens e com ensino superior completo. Tal perfil representa uma linha de continuidade em relação à composição social das feministas ao longo da história (Gomes e Sorj, 2014). No que se refere à sexualidade, por sua vez, observou-se a presença expressiva de lésbicas, tendo sido constante a participação das ativistas da Marcha das Vadias carioca em atos pela defesa da diversidade sexual. Em relação à identidade de gênero, as militantes são enfáticas na defesa do transfeminismo. A esse respeito, destaca-se a presença de uma ativista prostituta e travesti, e o envolvimento de várias das militantes que participaram da organização da Marcha das Vadias do Rio de Janeiro em atividades e eventos alinhados com o transfeminismo.

A transexualidade permanece definida como transtorno mental pela medicina psiquiátrica, e pessoas transexuais sofrem com diversas formas de discriminação e vivem em situação de vulnerabilidade (Bento, 2006; Borba, 2014; Almeida, 2012; Arán e Murta 2009; O’Dwyer, 2016). Mais recentemente, a transexualidade desponta também como uma identidade positiva e reivindicatória de direitos (Jesus, 2010).

À medida que a transexualidade ganha visibilidade pública através da politização das identidades trans e pelo acesso aos serviços de saúde, as 
pautas trans passam a fazer parte do movimento LGBTI e se aproximam do feminismo, fazendo frente ao momento político nacional conservador. No que se refere ao tratamento dado à transexualidade nos movimentos feministas, conforme já mencionado, verifica-se um embate.

O processo de integração das questões transexuais nas pautas feministas conduz a uma rearticulação da discussão identitária. A argumentação que recusa a entrada de mulheres trans em contextos feministas tem como base três noções principais: a de que essas mulheres passaram por uma socialização masculina que lhes dá privilégios que não podem ser relativizados; a de que tais mulheres não teriam experiências femininas essenciais tais como a menstruação e a maternidade; e, por fim, a de que mulheres trans estariam reproduzindo estereótipos de feminilidade que o movimento feminista vem tentando desconstruir. O "transfeminismo", em contraponto, representa a ideia de que mulheres transexuais também sofrem machismo e por isso sua luta política é também feminista. Dessa perspectiva, os argumentos das "feministas radicais" são caracterizados como "vaginistas", isto é, centrados apenas no órgão genital e, portanto, biologizantes e essencializadores. As transfeministas enfatizam, ainda, que nem todas as mulheres - cis $^{6}$ ou trans - possuem útero ou passam pela experiência de maternidade. Por fim, por mais que algumas mulheres trans reproduzam estereótipos, muitas mulheres cis também o fazem.

A categoria "transfobia" aparece como mobilizadora nesse debate, sendo, ao mesmo tempo, uma categoria acusatória e analítica. A palavra é análoga a "homofobia", termo que busca designar a rejeição/discriminação contra homens e mulheres homossexuais. "Transfobia", por sua vez, está conectada ao desrespeito à identidade de gênero.

\section{Radicalizando a democracia: o ideal de horizontalidade}

As ativistas envolvidas na organização da Marcha das Vadias do Rio de Janeiro, ainda que não se intitulassem como "novo feminismo", atribuíam à Marcha uma nova forma de organização política, menos marcada por hierarquias. O princípio da "horizontalidade" despontou como norteador central das militantes, servindo como critério de diferenciação em relação a um tipo de ativismo que caracterizavam como "institucionalizado".

\footnotetext{
"O termo "cis" refere-se àquelas pessoas cujo sexo designado no nascimento está "alinhado" à sua identidade de gênero. Ele vem sendo utilizado para apontar os privilégios dessas pessoas em relação a travestis e transexuais - daí o uso correlato de "cisnorma" e "cissexismo". É, portanto, um termo político que pretende evidenciar o caráter ilusório desse "alinhamento" (não nomeado porque naturalizado), bem como as consequências discriminatórias para as pessoas trans. Ver texto de Hailey Kaas em: <ensaiosdegenero.wordpress.com/2012/09/17/o-que-saopessoas-cis-e-cissexismo> (28 jan. 2016).
} 
Por se tratar de um espaço político sem representantes ou líderes, a Marcha era vista como um espaço em que mulheres se sentiam à vontade para começar a trajetória no feminismo, havendo maior liberdade para colocar opiniões. Tais preocupações alocam as reflexões produzidas pela Marcha das Vadias em um contexto mais amplo da luta democrática. Para além das demandas relativas à luta contra a violência de gênero e à defesa da liberdade sexual, ganha destaque o debate sobre formas de organização política da sociedade civil, tendo como horizonte práticas que fortaleçam a democracia. No atual contexto de difusão do ideário feminista, o modo de fazer política defendido pelas ativistas da Marcha poderia ser visto, nesse sentido, como parte importante dessa revitalização.

Simultaneamente, as representações sobre a Marcha das Vadias qualificam-na como um movimento divertido, ousado e irreverente, em contraponto ao passado do feminismo, cujos discursos são caracterizados como mais sérios. A dimensão lúdica se apresenta como uma marca geracional que atrai a juventude ao atribuir ao movimento um clima de festa e diversão. As imagens de jovens vestidas de maneira "provocante" "viralizam" nos meios de comunicação, ressignificando representações estigmatizantes e apresentando-as como alternativas libertadoras dos códigos normativos. O maior contingente de jovens em comparação a momentos anteriores do feminismo está relacionado, portanto, a um novo sentido atribuído a ser feminista, que, distanciado da categoria de acusação da "feminista mal-amada", comum nos anos 1980 como forma de deslegitimar as feministas, associa as jovens militantes à imagem, agora positivada, de ousadia e irreverência, de nãosubmissão e de controle sobre o próprio corpo.

Tal representação, ainda que atribua uma valoração positiva à Marcha das Vadias, também pode servir como categoria de acusação: a imagem da Marcha como um movimento "elitista e branco" vem acompanhada da ideia de falta de comprometimento com os problemas mais graves pelos quais passam as mulheres em situação de maior vulnerabilidade. Nesse sentido, a diversão na Marcha é contraposta a situações pelas quais passam, por exemplo, as moradoras de áreas marcadas pela violência urbana. Lá, não é possível brincar de ser vadia. Conforme disse, em entrevista concedida, uma ativista do grupo de mulheres de periferia Pagufunk: "Se eu aparecer na Baixada Fluminense com uma faixa escrito 'vadia' vou levar uma bíblia na cara". ${ }^{7}$ No mesmo sentido, uma ativista negra presente no processo de organização da

\footnotetext{
7 Pagufunk é um grupo de mulheres de periferia que, através de músicas de funk, fala sobre feminismo e o cotidiano nas periferias do Rio de Janeiro.
} 
Marcha das Vadias afirmou, em reunião de avaliação realizada posteriormente à Marcha de 2014: "O que se diz por aí é que é muito fácil ficar sem sutiã na praia de Copacabana". ${ }^{8}$

\section{"Enegrecendo o feminismo": as críticas de feministas negras à Marcha das Vadias}

A expressão "enegrecendo o feminismo" é utilizada por Sueli Carneiro (2003) para fazer referência à trajetória das mulheres negras no feminismo brasileiro. Em suas palavras,

Buscamos assinalar, com ela, a identidade branca e ocidental da formulação clássica feminista, de um lado; e, de outro, revelar a insuficiência teórica e prática política para integrar as diferentes expressões do feminino construídos em sociedades multirraciais e pluriculturais. [...] afirmamos e visibilizamos uma perspectiva feminista negra que emerge da condição específica do ser mulher, negra e, em geral, pobre [...] (Carneiro, 2003, p. 118).

A partir dessa condição específica, ativistas negras argumentam que a violência sexual incide sobre as mulheres negras de modo articulado com o racismo, baseando-se em estereótipos que as associam à promiscuidade sexual. As críticas das ativistas negras ao uso político do termo "vadia" argumentam que, para elas, tal categoria não denota liberdade, mas, pelo contrário, opressão. A Marcha das Vadias está focalizada na valorização de um tipo de imoralidade: saindo às ruas seminuas, com batons vermelhos e saias curtas, as ativistas contrapõem-se a concepções moralistas sobre sexualidade. O que significa, entretanto, valorizar a imoralidade para mulheres negras, historicamente desvalorizadas e exploradas sexualmente a partir do pressuposto de que seus corpos estão sempre disponíveis?

Poucas são as mulheres negras que participaram da organização da Marcha das Vadias do Rio de Janeiro de 2014, o que reflete a relevância das críticas ao uso político do termo vadia. Em uma das primeiras reuniões, uma delas discorreu sobre o impacto da diferença racial quando se está em espaços em que a maioria das pessoas é branca, e enfatizou a importância de que a dimensão racial fosse debatida nas reuniões de organização da Marcha. O

\footnotetext{
${ }^{8}$ A escolha da orla da praia de Copacabana para a realização da Marcha das Vadias carioca justificou-se por ser um local de prostituição. Conforme demonstra Julia O'Donnel (2013), no entanto, a orla atlântica da zona sul da cidade foi sendo construída ao longo dos anos como um território de distinção social, o que permanece até os dias de hoje na oposição entre as categorias de "zona sul" e "subúrbio". Essa oposição também apareceu nas entrevistas realizadas, sendo que a categoria de "subúrbio" foi substituída por "áreas de periferia".
} 
tema ganhou maior centralidade após um debate, organizado pelas ativistas, sobre aborto e violência obstétrica. Na ocasião, uma mulher negra que assistia sublinhou a ausência de debatedoras negras, e destacou que, mais uma vez, "as pretas e pardas aparecem como estatísticas". Não havia mulheres negras para falar sobre suas experiências, apesar de, como apontavam as debatedoras, serem elas as mais atingidas por essas questões. A partir dessa constatação, e tendo em vista o fato, já conversado entre as ativistas da Marcha, de que os feminismos negros têm críticas importantes à Marcha das Vadias, surgiu a proposta de um debate entre feministas negras e as organizadoras da Marcha das Vadias do Rio de Janeiro, o que era visto pelas participantes como um diálogo importante para o movimento.

Assim, a ativista que fizera a crítica no dia do debate se dispôs a ajudar a organizar um evento que congregasse ativistas da Marcha e feministas negras, tendo sido, para tal, incluída na lista de e-mails trocados entre as militantes. Quando da escolha da foto para a divulgação do evento, uma ativista da Marcha sugeriu uma foto descrita pela militante negra que ajudava a organizar o debate como "a de uma mulher preta anônima que pertence a alguma tribo africana". Registrou a "raiva" que sentiu ao ver a imagem e, frente às respostas que pontuavam a "ignorância" e "dificuldades" de encontrar uma imagem que fosse adequada, escreveu:

Entendo que não me cabe sugerir. É parte do exercício educativo que vocês, enquanto feministas brancas, concentrem esforços (leiam, discutam, reflitam etc.). Como preta não-vadia, posso colaborar avaliando se as escolhas que forem feitas apontam ou não para uma perspectiva antirracista.

Após mais algumas trocas, ativistas da Marcha enviaram longos e-mails explicitando os motivos pelos quais acreditavam que o princípio da construção coletiva e horizontal estava sendo perdido de vista. O entendimento era o de que as decisões que deveriam ser tomadas coletivamente estavam passando pela aprovação exclusiva da feminista negra. $\mathrm{O}$ fato de ela pertencer ao meio acadêmico, enquanto a ativista que havia proposto a foto era uma jovem que começava a participar de espaços feministas, além do fato de que esta havia se calado após as críticas da feminista negra, havia lhes feito perceber e apontar uma hierarquização entre quem detinha o conhecimento sobre o assunto (as "especialistas") e aquelas que "precisavam aprender sobre antirracismo". Entendiam que a vontade de propor das mais novas estava sendo desvalorizada.

Todas estavam preocupadas com a igualdade, mas interpretaram de maneiras distintas - e enfatizando diferentes marcadores sociais - as disputas 
que se estabeleciam. Assim, a interseccionalidade não se apresentava como unívoca entre raça e gênero, mas intervinha em relação à carreira profissional e militante para introduzir outros tipos de hierarquias.

\section{Considerações finais}

O conceito de interseccionalidade desponta como possibilidade de resolução das diferenças em uma perspectiva de emancipação e combate às opressões. As controvérsias entre correntes feministas da contemporaneidade apontam para a potencialidade dessa categoria para além da intersecção entre raça, gênero e classe, que fundamentou uma crítica contundente de ativistas negras ao feminismo hegemônico.

O transfeminismo, ao defender a legitimidade da participação de mulheres travestis e transexuais no movimento, se aproxima do feminismo interseccional pela proposta de diversificação de demandas. As críticas das "feministas radicais", em contraponto, são uma indicação dos problemas antevistos na implosão de categorias identitárias vistas como necessárias para a atuação política. Trata-se da reatualização de um embate histórico no feminismo, que remete à tensão entre igualdade e diferença e ao processo de recusa do essencialismo da categoria "mulher", com a busca do rompimento de dicotomias. Nesse debate, a desconstrução das identidades essenciais é vista por algumas feministas como um empecilho à ação política, na medida em que impediria a união em torno de objetivos em comum. Outras argumentam que descartar a suposta homogeneidade e unidade do sujeito é a condição necessária para a teorização sobre a multiplicidade de relações de subordinação.

Refletir sobre os embates em torno da questão identitária no feminismo permite iluminar temas mais amplos relativos a preceitos democráticos, evidenciando os problemas da efetivação da democracia representativa, uma vez que a recusa da entidade homogênea "mulher" leva à necessidade de que a luta contra a subordinação seja colocada de maneiras específicas (Mouffe, 2001; Preciado, 2011). Um dos modos de enfrentar essas questões é a partir da ideia de sujeitos plurais abarcados no conceito de "interseccionalidade". Uma tensão ainda não resolvida, porém, é a possibilidade de radicalização da democracia, expressa na noção, entre as ativistas da Marcha das Vadias do Rio de Janeiro, de "horizontalidade". A percepção, por parte das próprias militantes, da impossibilidade de efetivação completa desse ideal evidenciou a dimensão utópica da democracia direta, tendo em vista desigualdades estruturais entre as mulheres. Trata-se de uma tensão que não se restringe ao feminismo, dizendo respeito, de maneira mais ampla, às formas de organização da sociedade civil. Nas palavras de Chantal Mouffe, 
uno tiene que reconocer que una comunidad política completamente inclusiva nunca podrá existir. Siempre habrá un "afuera constitutivo", un exterior a la comunidad que es la condición misma de su existencia. Una vez que hemos admitido que no puede haber un "nosotros" sin un "ellos" y que todas las formas de consenso están basadas por necesidad en actos de exclusión, el problema ya no puede ser la creación de una comunidad completamente inclusiva donde el antagonismo, la división y el conflicto desaparecen (Mouffe, 2001, p. 9).

Pensar as hierarquias na efetivação da democracia nos espaços de atuação política implica considerar os diversos marcadores sociais da diferença e o modo como eles se entrelaçam nos contextos de interação. Carlos Eduardo Henning (2015) propõe o uso do termo "agência interseccional" para referir-se aos "espaços de ação calcados em marcadores sociais da diferença e que se dão em resposta aos cenários potenciais de desigualdades com as quais os sujeitos se confrontam" (Henning, 2015, p. 116). O autor enfatiza que não se trata de ignorar ou secundarizar os impactos das estruturas sociais não apenas na formação de identidades e subjetividades, mas também na própria capacidade de agência. Antes, trata-se de atentar igualmente para uma dimensão ainda virtualmente apagada no campo de estudos interseccionais, a saber:

os modos os quais os sujeitos potencialmente se utilizam de suas próprias marcas identitárias interseccionais (assim como na relação com os traços identitários interseccionais de outras pessoas) de modo a lidar com a criação, o questionamento e a desconstrução social de desigualdades (Henning, 2015, p. 117).

Esse parece ter sido o caso das ativistas negras nas interações em torno da Marcha das Vadias carioca: a partir da identidade de mulher negra, na qual se cruzam marcadores de vulnerabilidade, questionaram e procuraram desconstruir desigualdades, desestabilizando tal posição vulnerável.

No que se refere à geração, no entanto, isso não ocorreu. A clareza na exposição de ideias, bem como o grau de familiaridade com noções provenientes do meio acadêmico (dentre as quais a própria noção de interseccionalidade), foram fatores centrais na legitimação de falas. Por isso mesmo, as denúncias mais sistematizadas de hierarquias geracionais foram feitas por ativistas experientes. Isso pode ser explicado pela centralidade do ideal de consenso, que, ancorado em preceitos democráticos, paradoxalmente acaba por alocar em posições hierárquicas superiores as mais experientes, cujo conhecimento adquirido ao longo de uma trajetória militante/acadêmica as dota de um "capital de articulação política" (Bonetti, 2007), isto é, da habilidade 
de defender seus pontos de vista publicamente. Geração e capital simbólico são, portanto, marcadores sociais importantes nesses contextos, podendo ser abarcados no conceito de interseccionalidade, de modo a aprofundar reflexões relativas às hierarquias sociais.

A "interseccionalidade", assim como a "desontologização das identidades" proposta por Beatriz Preciado (2011), aparecem como estratégias que permitem que as diferentes experiências não sejam subsumidas na categoria "mulher", entendendo a identidade como relacional e não fixa. Se a atenção às diferenças e desigualdades entre as mulheres é imprescindível para o alcance do ideal de "horizontalidade" pretendido pelas ativistas da Marcha das Vadias, as tensões estão longe de serem completamente resolvidas, demonstrando que dilemas históricos se reatualizam e trazem novos questionamentos para os feminismos na contemporaneidade.

\section{Referências}

ADRIAO, Karla Galvão; TONELI, Maria Juracy; MALUF, Sônia Weidner. O movimento feminista brasileiro na virada do século 20: reflexões sobre sujeitos políticos na interface com as noções de democracia e autonomia. Revista de Estudos Feministas, v. 19, n. 3, p. 661-682, $2011<10.1590 /$ S0104-026X2011000300002>.

ALMEIDA, Guilherme Silva de. Repercussões sociais da assistência à saúde do transexual. In: Eloísio Alexsandro da Silva (org.). Transexualidade: princípios de atenção integral à saúde. São Paulo: Santos, 2012. p. 225-240.

ARÁN, Márcia; MURTA, Daniela. Do diagnóstico ao transtorno de identidade de gênero às redescrições da experiência da transexualidade: uma reflexão sobre gênero, tecnologia e saúde. Physis: Revista de Saúde Coletiva, v. 19, n. 1, p. 15-41, 2009 $<10.1590 /$ S0103-73312009000100003>.

BEAUVOIR, Simone de. O segundo sexo: a experiência vivida. São Paulo: Difusão Européia do Livro, 1960.

BENTO, Berenice. A reinvenção do corpo: sexualidade e gênero na experiência transexual. Rio de Janeiro: Garamond, 2006.

BONETTI, Alinne de Lima. Não basta ser mulher, tem de ter coragem: uma etnografia sobre gênero, poder, ativismo feminino popular e o campo político feminista de RecifePE. Tese (Doutorado) - Instituto de Filosofia e Ciências Humanas, Universidade Estadual de Campinas, Campinas, 2007.

BORBA, Rodrigo. Sobre os obstáculos discursivos para a atenção integral e humanizada à saúde de pessoas transexuais. Sexualidad, Salud y Sociedad, n. 17, p. 66-97, $2014<10.1590 / 1984-6487$. sess.2014.17.06.a>.

BUTLER, Judith. Problemas de gênero: feminismo e subversão da identidade. Rio de Janeiro: Civilização Brasileira, 2003. 236 p.

CARNEIRO, Sueli. Mulheres em movimento. Estudos Avançados, v. 17, n. 49, p. $117-132,2003<10.1590 /$ S0103-40142003000300008>. 
CRENSHAW, K. Demarginalizing the intersection of race and sex: a black feminist critique of antidiscrimination doctrine, feminist theory and antiracist politics. University of Chicago Legal Forum 1989, n. 1, p. 139-167, 1989.

GOMES, Carla de Castro. Nossos corpos, nossos manifestos. Cult, n. 219, p. 40-43, 2016.

GOMES, Carla; SORJ, Bila. Corpo, geração e identidade: a Marcha das Vadias no Brasil. Revista Sociedade e Estado, v. 29, n. 2, p. 433-447, $2014<10.1590 / \mathrm{S} 0102-$ 69922014000200007>.

HEILBORN, Maria Luiza. Usos e desusos do conceito de gênero. Cult, n. 219, p. 36-39, 2016.

HEILBORN, Maria Luiza; CABRAL, Cristiane da Silva. Sexualidad, género y color entre jóvenes brasileños. In: Peter Wade; Fernando Urrea; Mara Viveros (orgs.). Raza, etnicidad y sexualidades: ciudadanía y multiculturalismo em América Latina. Bogotá: Lecturas CES, 2008. p. 167-197.

HEMMINGS, Clare. Contando estórias feministas. Revista de Estudos Feministas, v. 17, n. 1, p. 215-241, $2009<10.1590 /$ S0104-026X2009000100012>.

HENNING, Carlos Eduardo. Interseccionalidade e pensamento feminista: as contribuições históricas e os debates contemporâneos acerca do entrelaçamento de marcadores sociais da diferença. Mediações, v. 20, n. 2, p. 97-128, 2015 $<10.5433 / 2176-6665.2015 \mathrm{v} 20 \mathrm{n} 2 \mathrm{p} 97>$.

JESUS, Jaqueline Gome de; ALVES, Hailey. Feminismo transgênero e movimentos de mulheres transexuais. Revista Cronos, v. 11, n. 2, p. 8-19, 2010.

O’DONNEL, Julia. A invenção de Copacabana: culturas urbanas e estilos de vida no Rio de Janeiro. Rio de Janeiro: Zahar, 2013.

MAYORGA, Claudia; COURA, Alba; MIRALLES, Nerea; CUNHA, Viviane. As críticas ao gênero e a pluralização do feminismo: colonialismo, racismo e política heterossexual. Estudos Feministas, v. 21, n. 2, p. 463-484, $2013<10.1590 /$ S0104026X2013000200003>.

MOUFFE, Chantal. Feminismo, ciudadanía y política democrática radical. In: Martha Lamas (org.). Ciudadanía y feminismo. México: Instituto Federal Electoral, 2001. p. 1-13.

O'DWYER, Brena. A construção do gênero nas relações: um estudo com mulheres trans jovens e sobre o processo de feminização. Rio de Janeiro, 2016. Dissertação de mestrado. Instituto de Medicina Social, Universidade do Estado do Rio de Janeiro.

PRECIADO, Beatriz. Multidões queer: notas para uma política dos "anormais". Estudos Feministas, v. 19, n. 1, p. 11-20, $2011<10.1590 /$ S0104-026X2011000100002>.

RODRIGUES, Carla. Coreografias do feminino. Florianópolis: Editora Mulheres, 2009.

RIBEIRO, Letícia. Somos todas vadias? Igualdade, diferença e política feminista a partir da Marcha das Vadias do Rio de Janeiro. Dissertação (Mestrado) - Instituto de Medicina Social, Universidade do Estado do Rio de Janeiro, Rio de Janeiro, 2016. 
SAFFIOTI, Heleieth. Conceituando o gênero. In: Carla Rodrigues; Luciana Borges; Tania Regina Oliveira Ramos (orgs.). Problemas de gênero. Rio de Janeiro: Funarte, 2016.

Recebido em: 29 maio 2017

Aprovado em: 18 fev. 2018

Autor correspondente:

Letícia Ribeiro

Rua Honório de Barros, 27/202 - Flamengo

22250-120 Rio de Janeiro, RJ, Brasil 